\title{
Tensile Response of Oxide/Oxide Woven Ceramic Composites
}

\author{
Dianyun Zhang*, Pascal Meyer ${ }^{\dagger}$ and Anthony M. Waas ${ }^{\ddagger}$ \\ Aerospace Engineering, University of Michigan, Ann Arbor, MI, 48109
}

\begin{abstract}
Room-temperature tensile responses of oxide-oxide woven ceramic matrix composites (CMCs) have been studied for two different lay-ups, including $[0 / 90]_{s}$ and $[+45 / 0 /-45 / 0]_{s}$. The CMC is made of aluminosilicate matrix reinforced by $3 \mathrm{M} \mathrm{Nextel}{ }^{\mathrm{TM}} 610$ alumina fibers (AS/N610). The dry fiber preform consists of multiple layers of eight-harness satin weave (8HSW) fabric. The digital image correlation (DIC) technique was utilized to map the deformation histories and identify modes of failure for both un-notched and single-edgenotched tension tests. A lamina-level constitutive model was developed for a single 8HSW CMC ply. It is assumed that the pre-peak nonlinear response is only attributed to the in-plane shear. The post-peak strain softening responses were related to the tractionseparation laws through the smeared crack approach. Utilizing the ply properties measured from the un-notched $[0 / 90]_{\mathrm{s}}$ and $[+45 / 0 /-45 / 0]_{\mathrm{s}}$ tension tests, the proposed computational model shows accurate predictions for the single-edge-notched tension tests.
\end{abstract}

\section{Introduction}

Oxide-oxide ceramic matrix composites (CMCs) have emerged as candidates for many high-temperature structural applications including those in the aerospace and gas turbine industry. ${ }^{1}$ Previous studies have shown that continuous fiber-reinforced CMCs can maintain high strength in the presence of holes and notches, ${ }^{1,2}$ exhibiting considerable damage tolerance under various loading conditions in service.

It has been reported by a number of researchers that CMCs can exhibit progressive non-elastic deformation prior to two-piece failure due to the occurrence of progressive matrix cracking which acts to dissipate energy. ${ }^{3,4,5,6}$ In order to fully understand the effect of matrix microcracking on the composite macroscopic response, micromechanical analysis must be employed at the fiber and matrix scale. The matrix material in CMCs contains a relatively high content of porosity and voids, resulting in difficulty in characterizing the matrix in-situ properties. In addition, multiple failure mechanisms have been observed for woven CMCs subjected to uniaxial tension, including fiber breakage, matrix cracking in-between fiber tows, matrix intratow cracking, and delamination between adjacent plies. Modeling the details of these failure modes requires further investigation on the failure initiation and progression at the microscale.

Alternatively, constitutive models can be developed at the lamina level by utilizing the experimental results of laminates with $0^{\circ}, 90^{\circ}$, and $\pm 45^{\circ}$ lay-ups. Each ply is assumed to be a homogeneous orthotropic solid, and the nonlinear stress-strain relation is directly implemented to the constitutive model without using micromechanical consideration. The evolution of damage and failure can be captured via a stiffness degradation scheme based upon continuum damage mechanics (CDM). CDM shows a distinct computational advantage by treating distributed cracking within an effective continuum by scaling the area of damage with respect to a finite volume. In the CDM theory, the degradation of the material stiffness matrix is modeled using a set of scalar damage variables that are associated with certain observed failure mechanisms. The idea of using scalar damage variables was first proposed by Kachanov. ${ }^{7}$ Starting with the pioneering work of Talreja, ${ }^{8}$ a number of practical applications of CDM were published. ${ }^{9,10,11,12,13,14,15,16}$ Implementation of CDM in modeling damage and failure in polymer composite materials has been reported in, ${ }^{8,17,18,19,20,21,22}$ where single or multiple damage variables have been proposed.

*Postdoctoral Research Fellow, Aerospace Engineering, University of Michigan, Ann Arbor, MI, 48109

${ }^{\dagger} \mathrm{PhD}$ Candidate, Aerospace Engineering, University of Michigan, Ann Arbor, MI, 48109

${ }^{\ddagger}$ Felix Pawlowski Professor, Aerospace Engineering, University of Michigan, Ann Arbor, MI, 48109. Fellow AIAA 
Although CDM has the ability to capture material strain softening behavior, each damage variable used in CDM is associated with a unique damage mode that needs to be determined from a specially designed experiment. Characterization of these variables is required for each material system with different lay-ups and loading conditions. In addition, this method can lead to pathological mesh dependency if the post-peak stress-strain response is not associated with a characteristic length scale that is related to the mechanism of damage evolution. When implementing CDM in a FE framework, failure will be localized within a single element, and the energy dissipated due to failure becomes a function of element size. In essence, the element size becomes the characteristic length. Consequently, in the limit of zero element size, the amount of energy dissipation approaches zero. In order to restore mesh objectivity, that is, to prevent element size from being the characteristic length, nonlocal theory ${ }^{23,24}$ and gradient-based theory ${ }^{25,26}$ have been developed by enforcing a characteristic length, which is independent of element size, to be associated with damage evolution equations.

An alternative method to preserve mesh objectivity is to associate the post-peak strain softening behavior with a traction-separation law such that the total strain energy dissipated during the failure process can be equated to the fracture toughness of the material, thereby introducing a characteristic element length which is related to energy dissipation. Both the crack band ${ }^{27}$ approach and smeared crack approach (SCA) ${ }^{28}$ have been developed with this motivation. In these theories, the pre-peak stress-strain response is modeled using a standard continuum theory (such as elasticity, plasticity and Schapery theory ${ }^{10}$ ), while the postpeak strain softening failure behavior is represented through a traction-separation law that incorporates a characteristic length. This characteristic length is related to element size through an equation that includes material properties, including fracture toughness, fracture strength, and elastic modulus. Implementation of various failure initiation criteria and subsequent evolution laws for modeling progressive failure in composite materials has been reported in. ${ }^{29,30,31,32}$ Recently, Pineda et al. ${ }^{33}$ investigated the capability of utilizing the crack band theory to predict the progressive matrix cracking within a fiber-matrix microstructure.

The purpose of this study is to investigate the tensile response of oxide/oxide woven CMCs with two different lay-ups, including $[0 / 90]_{\mathrm{s}}$ and $[+45 / 0 /-45 / 0]_{\mathrm{s}}$. Details of the material microstructure used in this paper is given in Section II. Room-temperature tension tests were carried out on both un-notched and singleedge-notched specimens, as discussed in Section III. A lamina-level constitutive model was developed for both pre-peak nonlinear responses and post-peak strain softening, as presented in Section IV. Using the material properties obtained from the un-notched tests, the proposed model demonstrates accurate predictions for the notched tests, as shown in Section V.

\section{Material System}

The woven CMCs used in this study were manufactured by COI Ceramics, Inc., San Diego, CA. The CMC is made of aluminosilicate matrix reinforced by $3 \mathrm{M}$ Nextel ${ }^{\mathrm{TM}} 610$ alumina fibers, referred to as AS/N610. The dry fiber preform consists of multiple layers of $8 \mathrm{HSW}$ fabric. Different layers of eight-harness satin weave (8HSW) fabric are stacked together with predefined orientations, as a laminate. The stacking sequences and panel thicknesses of the two different architectures investigated in this paper are summarized in Table 1. Here, $0^{\circ}$ designates the direction along the warp fiber tow (weaver), while $90^{\circ}$ designates the weft (fill) direction. Therefore, the specimen that contains fiber tows running parallel to the panel edge is defined as a [0/90] laminate, while others contain woven fabric rotated by $\pm 45^{\circ}$. A close-up image of the polished cross-sectional surface of the $[0 / 90]_{\mathrm{s}}$ lay-up is shown in Figure 1. The optical micrograph shows a certain amount of porosity in the as-fabricated composite panels, indicating the importance of characterizing the material in-situ responses to account for these imperfections.

Table 1. Two different lay-ups of CMCs studied in this paper.

\begin{tabular}{cc}
\hline Lay-up & Thickness $(\mathrm{mm})$ \\
\hline$[0 / 90]_{\mathrm{s}}$ & $0.762 \pm 0.025$ \\
{$[+45 / 0 /-45 / 0]_{\mathrm{s}}$} & $1.524 \pm 0.025$ \\
\hline
\end{tabular}




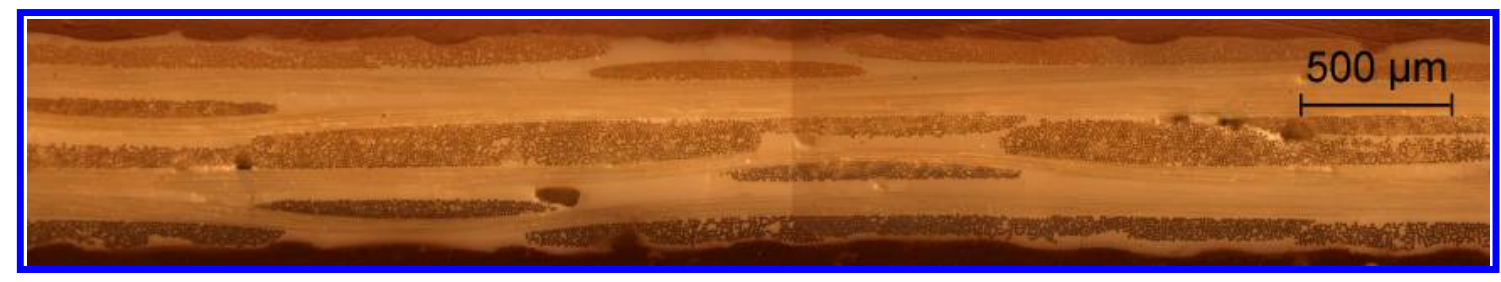

Figure 1. Optical micrograph of the cross-sectional surface of the $[0 / 90]_{\mathrm{s}}$ lay-up.

\section{Experiment}

Uniaxial tension tests were carried out on both un-notched and single-edge-notched specimens to determine the tensile responses of the two different lay-ups and to characterize notch sensitivity. Dogbone tension specimens were cut at Cincinnati Testing Laboratories Inc., OH, with a gauge length of 4.5 in and a gauge width of $0.9 \mathrm{in}$. The edge-notch has a diameter of 0.125 in and a depth of 0.09 in, as schematically shown in Figure 2. Tension tests were performed using a hydraulically activated Shore Western load frame at a loading rate of $0.0001 \mathrm{in} / \mathrm{sec}$ to achieve a quasi-static loading condition. In order to investigate the failure modes associated with the deformation histories, the outer surface of the specimen was speckled using black paint so that the full field strain histories can be obtained via a digital image correlation (DIC) technique. Images of the front speckled surface were taken during the deformation using a 5 Megapixel Grasshopper camera at 0.5-s time intervals. These images were analyzed using the DIC software DaVis (version 8.1.2) to determine the surface strain responses. The effective strains of the specimen were determined by averaging the surface strains over the area where the strain distribution was uniform. Fiberglass tabs were attached to both sides of the grip section to prevent crushing of the specimens.

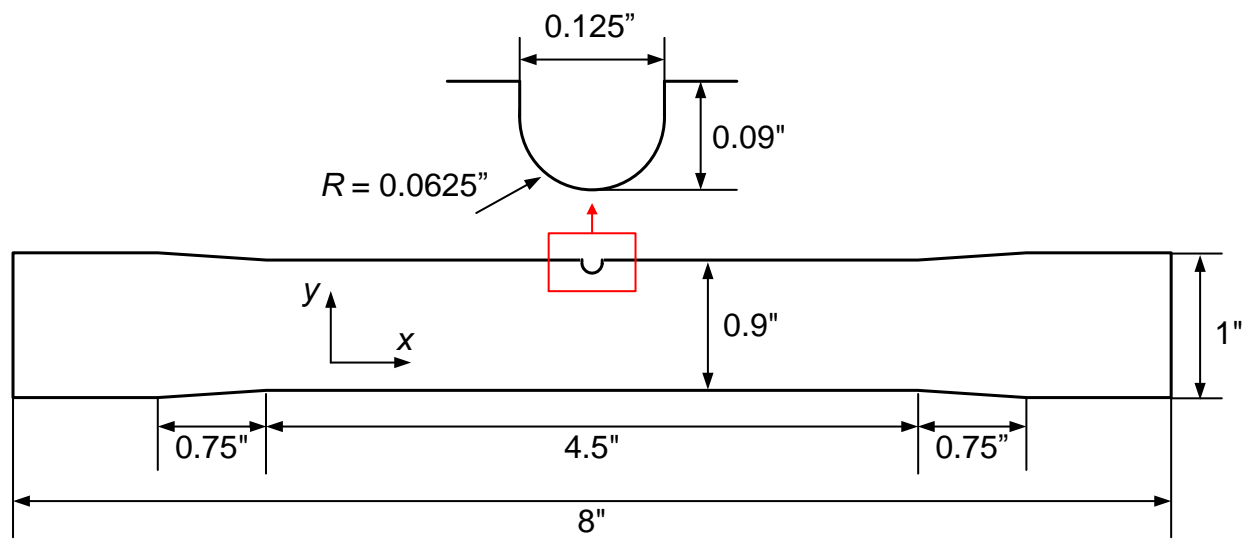

Figure 2. Dimension of the single-edge-notched specimen.

The uniaxial stress versus strain responses for the $[0 / 90]_{\mathrm{s}}$ un-notched specimens are shown in Figure 3 , and the surface strain contours at the annotated points are plotted in Figure 4. The areas of strain localization indicate the sites of onset of cracking. These cracks appear to initiate mostly at the edges of the specimen, while some higher strain regions are visible on the interior as well. The stress-strain response shows nearly linear elastic behavior up to failure. Fiber tow breakage, as shown in Figure 5, was determined as the dominant mode of failure that results in the two-piece failure leading to a load drop. The breaking of fibers also caused matrix cracks to spread out over the specimen across the entire gauge width, as evident in Figure 6. The elastic tensile modulus for the $[0 / 90]_{\mathrm{s}}$ lay-up was determined to be $114.9 \pm 10 \% \mathrm{GPa}$, and the tensile strength and strain to failure were $556.4 \pm 6 \% \mathrm{MPa}$ and $0.0048 \pm 14 \%$, respectively.

Figure 7 shows the stress versus strain responses for the $[+45 / 0 /-45 / 0]_{\mathrm{s}}$ un-notched specimens. Following the initial linear response, the onset of nonlinearity occurs at about $20 \%$ of the ultimate strength. The presence of $45^{\circ}$ fibers resulted in strain localization and formation of shear bands at a $45^{\circ}$ angle with respect to the loading axis, as evident from the DIC results shown in Figure 8. This finding is similar to that reported in. ${ }^{2,34}$ The elastic tensile modulus for the $[+45 / 0 /-45 / 0]_{\mathrm{s}}$ lay-up was $110.9 \pm 5 \% \mathrm{GPa}$. The ultimate tensile strength and strain to failure were $267.4 \pm 9 \% \mathrm{MPa}$ and $0.0041 \pm 13 \%$, respectively. It should be noted 


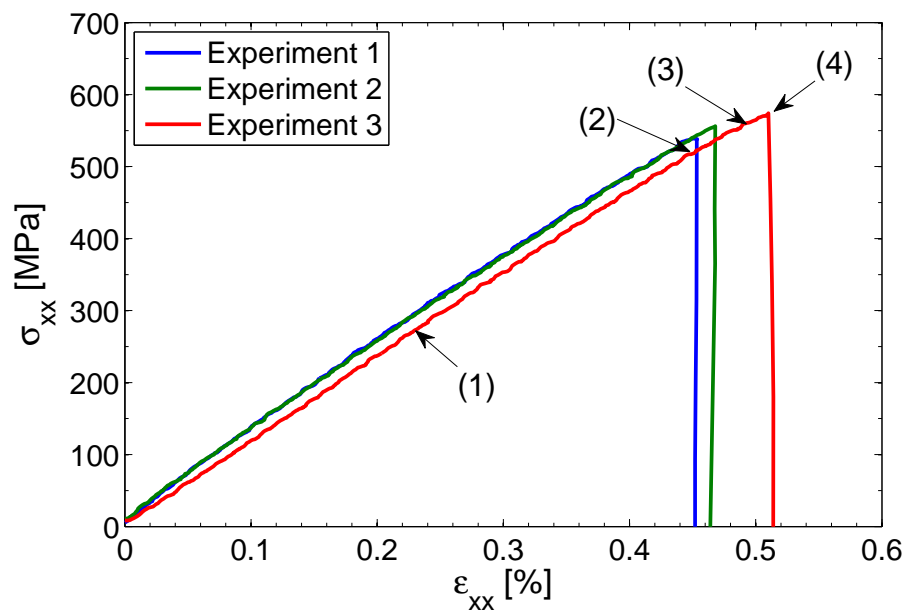

Figure 3. Tensile stress versus strain responses for the $[0 / 90]_{\mathrm{s}}$ un-notched specimens.

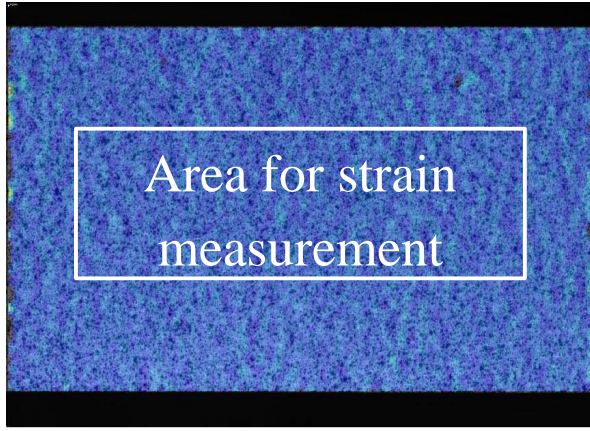

(a) At point (1)

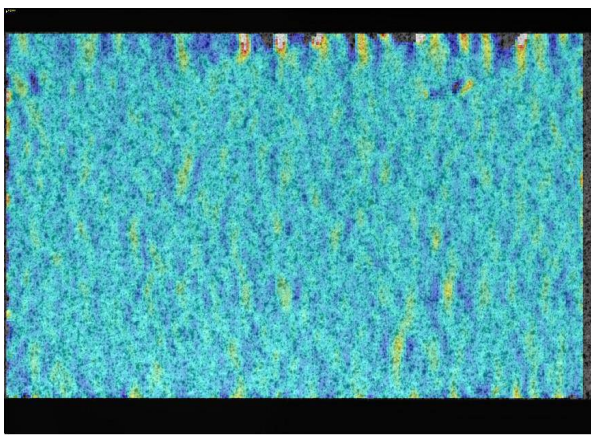

(c) At point (3)

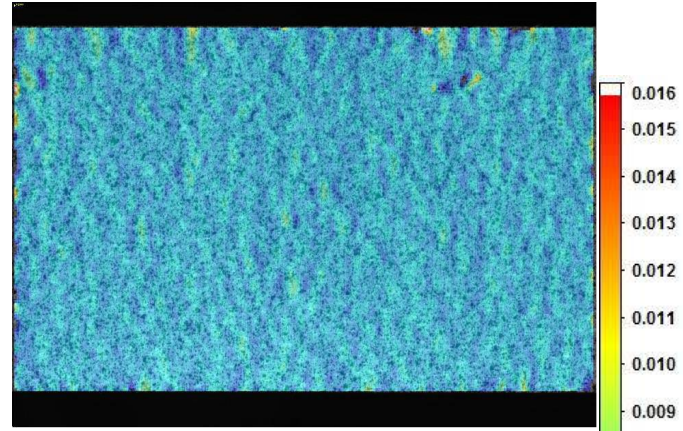

(b) At point (2)

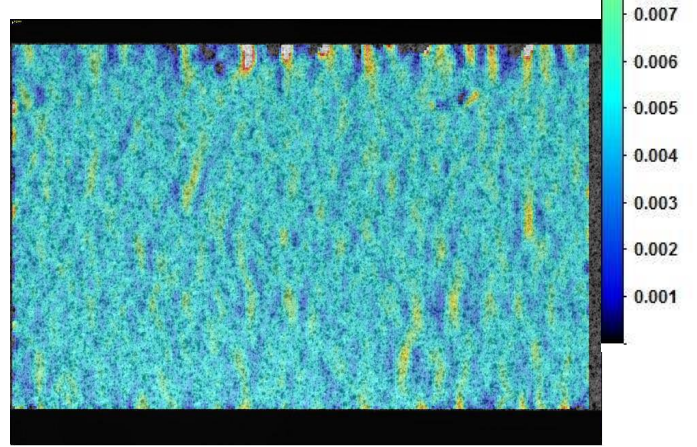

(d) At point (4)

Figure 4. Strain contour plots overlaid on the $[0 / 90]_{\mathrm{s}}$ un-notched specimen. Areas of strain localization indicate the sites of onset of matrix cracking. These images are correlated to the labeled points shown in Figure 3 .

that the $45^{\circ}$ layer has little influence on the initial tensile stiffness, and the reported elastic modulus is only $2 \%$ lower than the $[0 / 90]_{\mathrm{s}}$ specimens. However, the progression of matrix cracking results in a $50 \%$ lower ultimate strength value compared with the $[0 / 90]_{\mathrm{s}}$ lay-up.

The uniaxial stress-strain responses for the single-edge-notched specimen with a $[0 / 90]_{s}$ lay-up are shown in Figure 9. The stress was calculated by normalizing the grip load by the narrowest width of the gauge section, and the effective strains were computed by taking the average over the surface area away from the notched edge, as shown in Figure 10(a). The presence of the edge notch introduced strain concentrations that initiated matrix cracking earlier compared with the un-notched specimens. The surface strain contours 


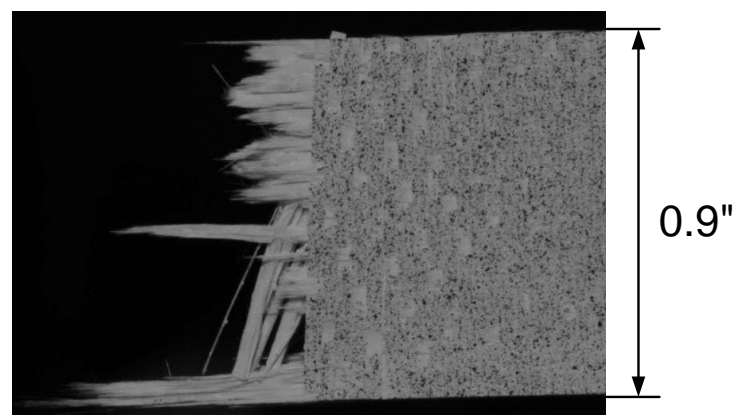

Figure 5. Fracture surface of the $[0 / 90]_{\mathrm{s}}$ un-notched specimen.

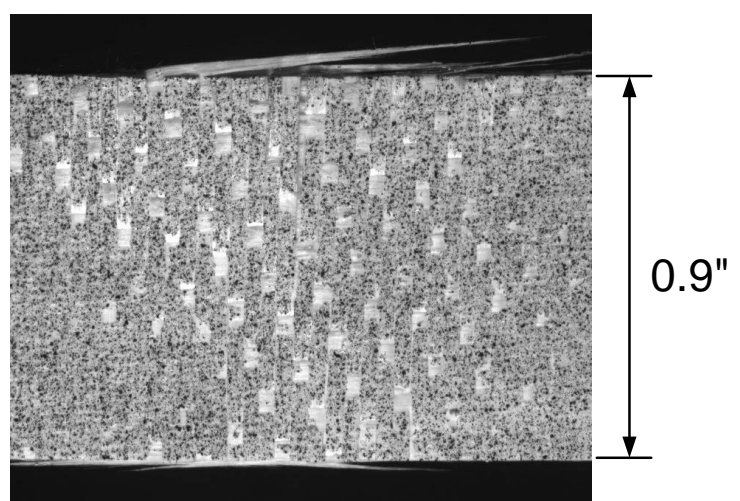

Figure 6. Post-test image shows matrix cracks spreading out over the entire gauge width of the $[0 / 90]_{\mathrm{s}}$ un-notched specimen.

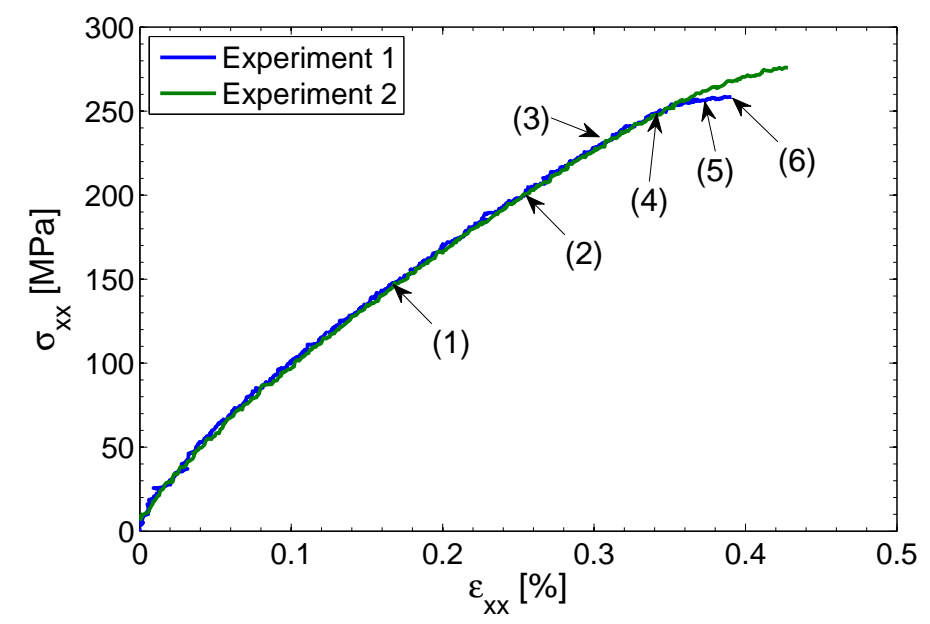

Figure 7. Tensile stress versus strain responses for the $[+45 / 0 /-45 / 0]_{\mathrm{s}}$ un-notched specimens.

at various loading levels are shown in Figure 10. Two initial sites of axial strain localization were observed in regions of high shear loading. This finding indicates that the failure of the $[0 / 90]_{\mathrm{s}}$ single-edge-notched specimen is initiated by the shear degradation of the woven CMC ply, which causes large local shear strains, leading to failure by tension. The final load drop was attributed to fiber fracture, followed by the spread of matrix cracking across the gauge section. The ultimate tensile strength for the $[0 / 90]_{s}$ edge-notched specimen was $361.0 \pm 16.4 \% \mathrm{MPa}$, which is $35 \%$ lower than the strength of the un-notched specimens. Therefore, the presence of the edge notch reduces the ultimate strength significantly for the $[0 / 90]_{\mathrm{s}}$ lay-up. 


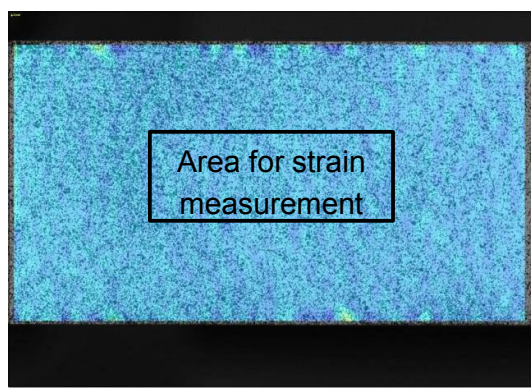

(a) At point (1)

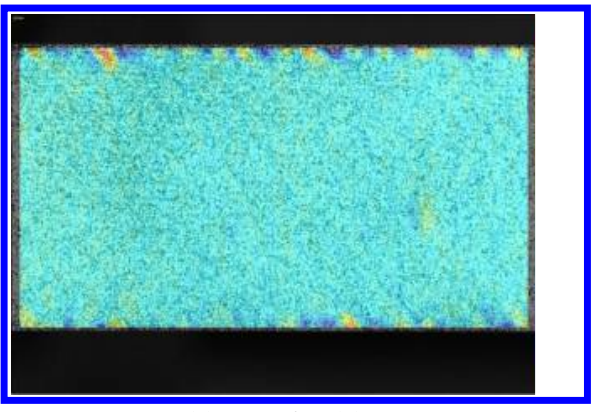

(c) At point (3)

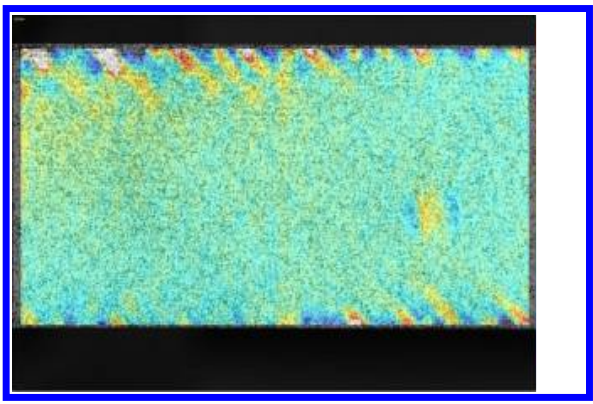

(e) At point (5)

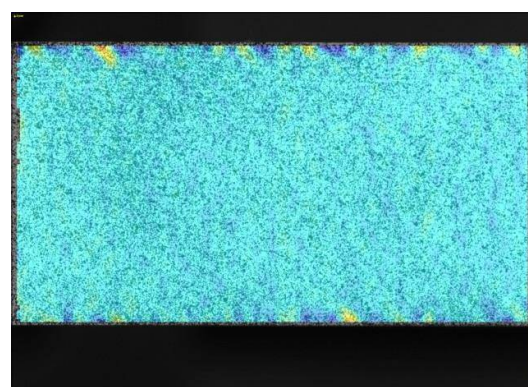

(b) At point (2)

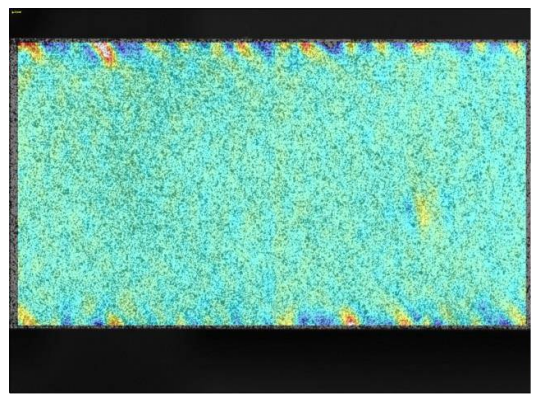

(d) At point (4)

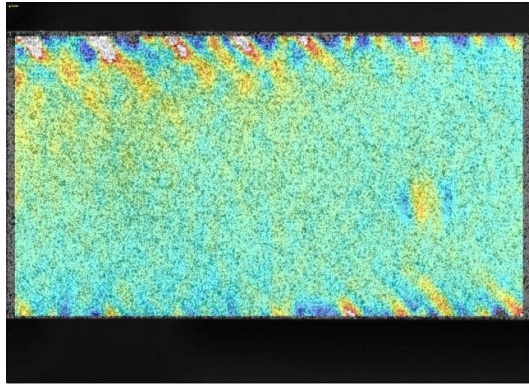

(f) At point (6)

Figure 8. Strain contour plots overlaid on the $[+45 / 0 /-45 / 0]_{\text {s }}$ un-notched specimen. The presence of $45^{\circ}$ fibers results in strain localization and shear band formation at a $45^{\circ}$ angle with respect to the loading axis. These images are correlated to the labeled points shown in Figure 7.

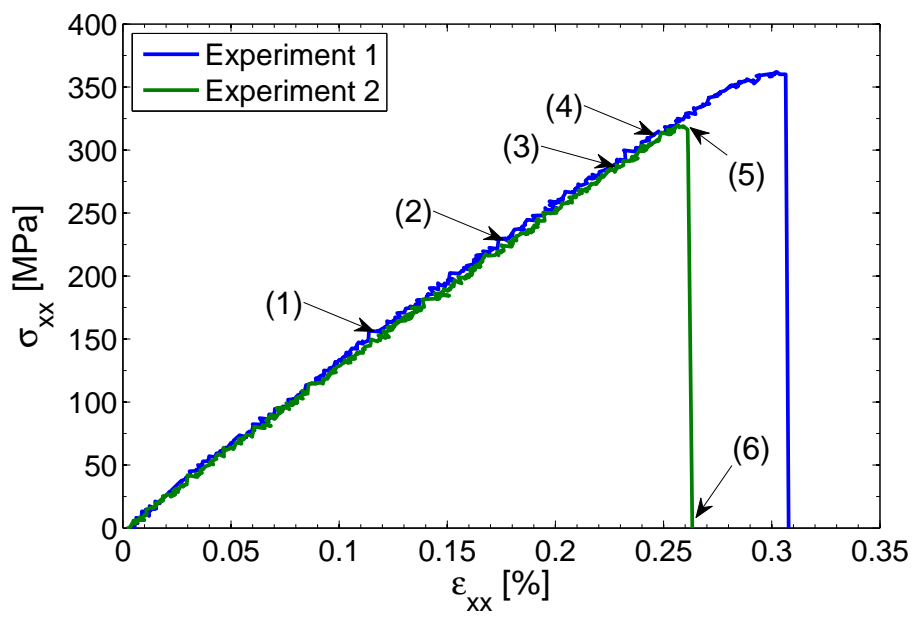

Figure 9. Tensile stress versus strain responses for the $[0 / 90]_{\mathrm{s}}$ single-edge-notched specimens. 


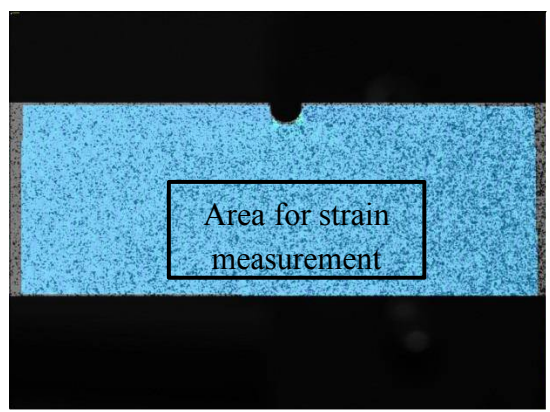

(a) At point (1)

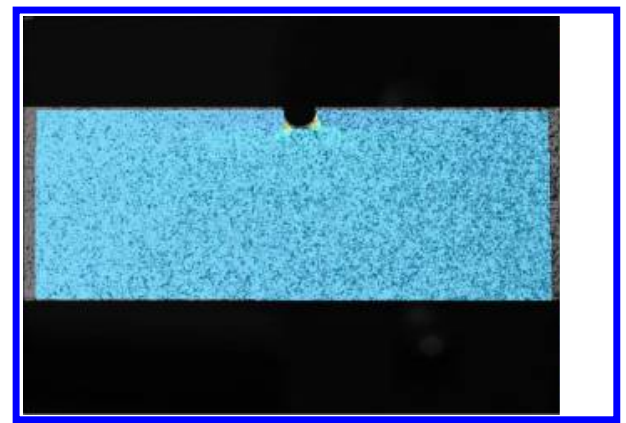

(c) At point (3)

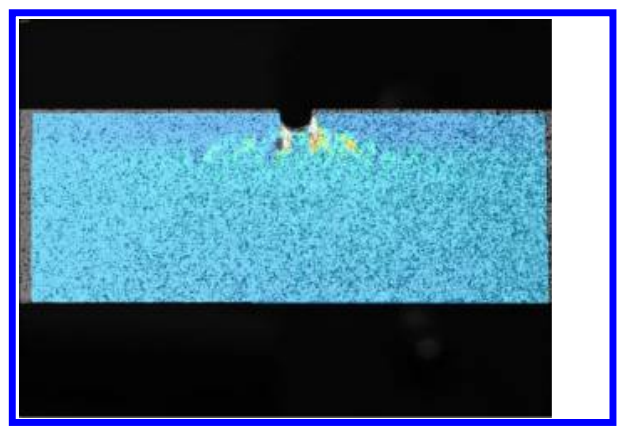

(e) At point (5)

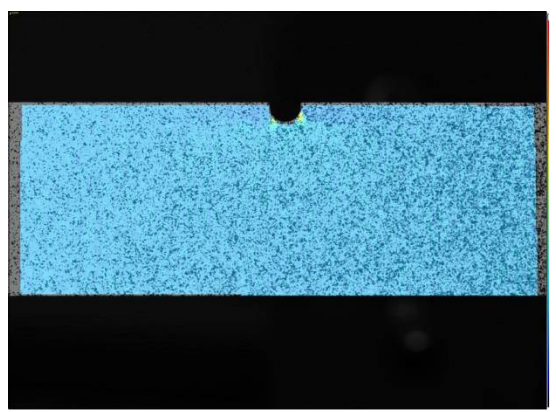

(b) At point (2)

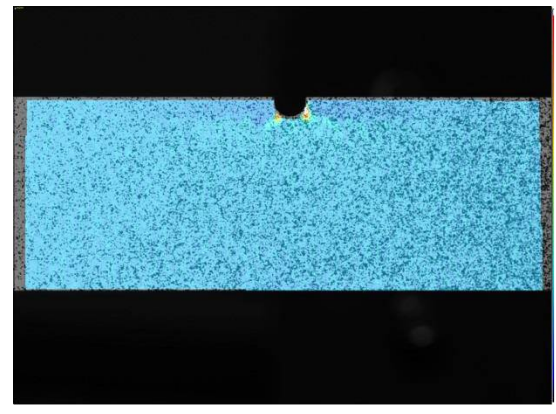

(d) At point (4)

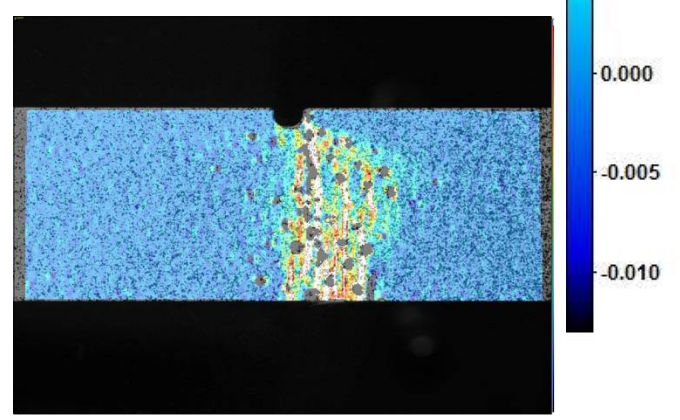

(f) At point (6)

Figure 10. Strain contour plots overlaid on the $[0 / 90]_{\mathrm{s}}$ single-edge-notched specimen. Two initial sites of strain localization developed in regions around the edge notch. The final fracture occurred on one side of the notch and cracks were spread over the gauge section in the post-fracture specimen. These contour plots are correlated to the labeled points shown in Figure 9. 


\section{Computational Model}

\section{IV.A. Construction of the Finite Element (FE) model}

The computational strategy adopted was motivated by the experimental findings of failure mechanisms. The woven CMCs were modeled using a full 3D FE model consisting of discrete homogeneous layers to account for different lay-ups. A new constitutive law was developed to model the effective responses of a single ply of $8 \mathrm{HSW}$, including both pre-peak nonlinear evolution and post-peak softening. The 8HSW was homogenized as an orthotropic solid with "1" and "2" designating the major fiber axes, as schematically shown in Figure 11. Each effectively homogenized layer was meshed using 3D linear brick elements, and the constitutive relation was implemented at each integration point through a user defined material subroutine, UMAT. This subroutine is called at each time increment, and the material constitutive law is updated through user-defined options. In the present study, inter-ply delamination was not accounted for, because it was not observed as a significant mechanism of failure, therefore, displacement continuity was enforced across the boundary of the two adjacent layers. The FE analysis was carried out using the Abaqus/Standard (version 6.12) dynamic implicit solver.

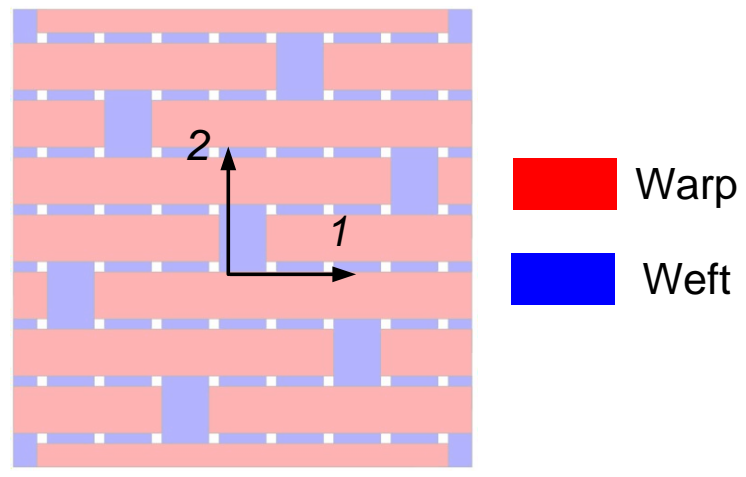

Figure 11. Homogenization of a single $8 \mathrm{HSW}$ CMC layer. "1" and "2" designate the two major fiber axes.

\section{IV.B. Pre-peak Response}

The constitutive model for the effective response of each 8HSW ply was developed based upon the experimental observation of the $[0 / 90]_{\mathrm{s}}$ and $[+45 / 0 /-45 / 0]_{\mathrm{s}}$ un-notched tension tests. For the $[0 / 90]_{\mathrm{s}}$ lay-up, the stress-strain relation shows a linear response upto failure, whereas the $[+45 / 0 /-45 / 0]_{\mathrm{S}}$ lay-up shows significant nonlinearity. Thus, in the pre-peak regime, it is assumed that the ply nonlinear behavior is only attributed to the in-plane shear loading, and the nonlinearity is independent of the normal components. It is further assumed that the stress-strain responses are the same along the 1-and 2-directions. The effective elastic Young's moduli, Poisson's ratio, and shear modulus of a single 8HSW layer can be obtained from the uniaxial tension tests, and the results are summarized in Table 2. The ply stiffness matrix can be written as,

$$
\left\{\begin{array}{l}
\epsilon_{11} \\
\epsilon_{22} \\
\epsilon_{33} \\
\gamma_{12} \\
\gamma_{13} \\
\gamma_{23}
\end{array}\right\}=\left[\begin{array}{cccccc}
\frac{1}{E_{1}} & -\frac{\nu_{12}}{E_{1}} & -\frac{\nu_{13}}{E_{1}} & 0 & 0 & 0 \\
-\frac{\nu_{12}}{E_{1}} & \frac{1}{E_{2}} & -\frac{\nu_{23}}{E_{2}} & 0 & 0 & 0 \\
-\frac{\nu_{13}}{E_{1}} & -\frac{\nu_{23}}{E_{2}} & \frac{1}{E_{3}} & 0 & 0 & 0 \\
0 & 0 & 0 & \frac{1}{G_{12}^{s}} & 0 & 0 \\
0 & 0 & 0 & 0 & \frac{1}{G_{13}} & 0 \\
0 & 0 & 0 & 0 & 0 & \frac{1}{G_{23}}
\end{array}\right]\left\{\begin{array}{l}
\sigma_{11} \\
\sigma_{22} \\
\sigma_{33} \\
\tau_{12} \\
\tau_{13} \\
\tau_{23}
\end{array}\right\}
$$

where $G_{12}^{s}$ is the secant in-plane shear modulus that captures the nonlinear shear evolution as shown in Figure 12. It is assumed that the nonlinear shear stress versus shear strain relation can be characterized using an exponential relation as,

$$
\tau_{12}=\tau_{12}^{y}-\frac{K_{1}}{K_{2}}\left(\mathrm{e}^{-K_{2} \tau_{12}}-\mathrm{e}^{-K_{2} \frac{\tau_{12}^{y}}{G_{12}^{e}}}\right)
$$


where $G_{12}^{e}$ is the elastic shear modulus, $\tau_{12}^{y}$ is the yield shear stress in the pure shear, and $K_{1}$ and $K_{2}$ are the two material constants that govern the nonlinear progression. These nonlinear properties were obtained from the $[+45 / 0 /-45 / 0]_{\mathrm{s}}$ tension test, and the values are summarized in Table 3 . It is also assumed that there is no damage progression along the 3 -direction, as a result, $E_{3}=E_{1}=E_{2}, G_{13}=G_{23}=G_{12}^{e}$, and $\nu_{13}=\nu_{23}=\nu_{12}$.

Table 2. The effective elastic properties of a single $8 \mathrm{HSW}$ CMC ply used in the FE model.

\begin{tabular}{cccc}
\hline $\begin{array}{c}E_{1} \\
(\mathrm{GPa})\end{array}$ & $\begin{array}{c}E_{2} \\
(\mathrm{GPa})\end{array}$ & $\begin{array}{c}\nu_{12} \\
-\end{array}$ & $\begin{array}{c}G_{12} \\
(\mathrm{GPa})\end{array}$ \\
\hline 115.0 & 115.0 & 0.3 & 44.0 \\
\hline
\end{tabular}

Table 3. Nonlinear in-plane shear properties used in this paper.

\begin{tabular}{ccc}
\hline$\tau_{12}^{y}(\mathrm{MPa})$ & $K_{1}(\mathrm{MPa})$ & $K_{2}$ \\
\hline 26.4 & $9 \mathrm{e}^{4}$ & 2000 \\
\hline
\end{tabular}

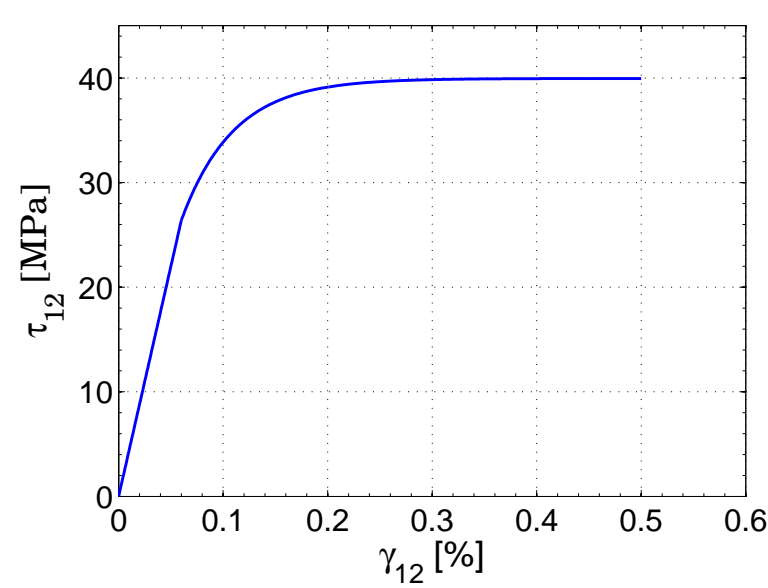

Figure 12. Nonlinear shear response used in the FE model.

\section{IV.C. Post-peak Softening Responses}

Fiber fracture and in-plane shear failure are the two dominant damage and failure modes observed in the experiment. In the present model, the effects of these failure modes can be incorporated through the degradation of material stiffness matrix. However, it should be noted that these modes of failure result in a loss of load-carrying capability, followed by a post-peak strain softening in the stress-strain response. Since the positive definiteness of the material tangent stiffness matrix is lost in the softening regime, the FE method will provide mesh dependent results if no characteristic length is introduced. ${ }^{27,35}$ In the present study, the ply post-peak response was modeled using the SCA by assuming the existence of the two observed failure modes. The general formulation of the SCA and the choice of the characteristic length scale are given in Section IV.C.1 and IV.C.2, respectively. The implementation of the SCA for modeling the failure progression in a single 8HSW ply is discussed in Section IV.C.3.

\section{IV.C.1. SCA Formulation}

The key assumption of the SCA is that when failure does initiate, the total strain, $\boldsymbol{\epsilon}$, is decomposed into a continuum strain, $\boldsymbol{\epsilon}^{c o}$, and a non-continuum contribution, referred to as the cracked strain, $\boldsymbol{\epsilon}^{c r}$, as ${ }^{28}$

$$
\epsilon=\epsilon^{c o}+\epsilon^{c r}
$$


In a continuum scheme, $\boldsymbol{\epsilon}^{c o}$ can be further decomposed into elastic, plastic, and thermal strains, if they are present. In the current study, the nonlinear shear response is modeled using a secant-modulus approach, as shown in Section IV.C. Thus, the secant strains at the onset of failure initiation are used for $\boldsymbol{\epsilon}^{c o}$. Here, $\boldsymbol{\epsilon}$, $\boldsymbol{\epsilon}^{c o}$, and $\boldsymbol{\epsilon}^{c r}$ are presented in the global coordinates.

Figure 13 shows the crack morphology in 3D. At the crack interface, there exist three relative displacements between the crack faces. One is the crack opening displacement, and the other two are the crack sliding displacements. The subscript $n$ and $t$ are used to designate the directions normal to the crack and tangential to the crack, respectively. In the SCA, the crack strains are embedded into a continuum, hence, the mode-I crack opening displacement is represented by a local smeared normal crack strain, $\epsilon_{n n}^{c r}$, and the two mode-II crack sliding displacements are replaced by two local smeared shear crack strains, $\gamma_{t 1}^{c r}$ and $\gamma_{t 2}^{c r}$. These local crack strains are defined in the local coordinates that incorporate crack orientation, and can be related to the global coordinates through a transformation matrix, $\boldsymbol{N}$, as,

$$
\boldsymbol{\epsilon}^{c r}=\boldsymbol{N} \boldsymbol{e}^{c r}=\boldsymbol{N}\left\{\begin{array}{c}
\epsilon_{n n}^{c r} \\
\gamma_{t 1}^{c r} \\
\gamma_{t 2}^{c r}
\end{array}\right\}
$$

where $\boldsymbol{e}^{c r}$ is a vector that contains local crack strains. For a single crack, $\boldsymbol{N}$ is a 6 by 3 transformation matrix depending on crack orientation. The derivation for $\boldsymbol{N}$ in terms of the direction cosines of the crack plane is given in. ${ }^{36}$

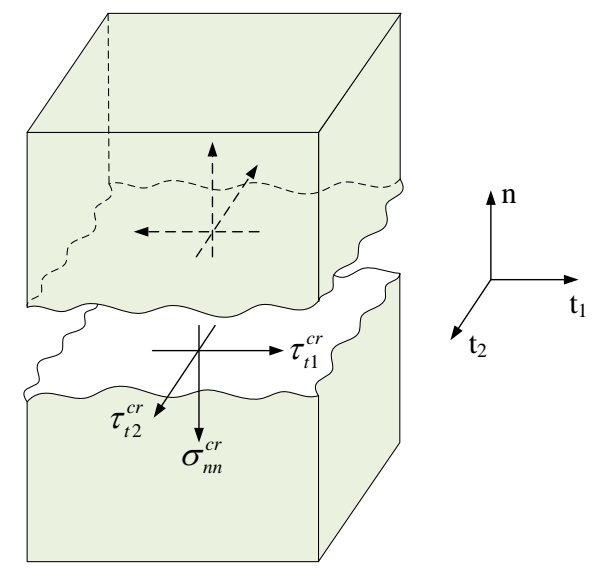

Figure 13. Crack morphology. There exist one normal and two shear crack components at the crack interface in a $3 \mathrm{D}$ stress state.

For a single $8 \mathrm{HSW}$ ply, it is assumed that cracks are aligned with the two major fiber directions. Since the 1- and 2-directions are equivalent for a woven ply, two cracks are allowed to propagate along the fiber directions at each integration point of the FE model. The local crack strains that contain two independent cracks are, ${ }^{37}$

$$
\boldsymbol{e}^{c r}=\left[\begin{array}{llllll}
\epsilon_{n n 1}^{c r} & \gamma_{t 11}^{c r} & \gamma_{t 12}^{c r} & \epsilon_{n n 2}^{c r} & \gamma_{t 21}^{c r} & \gamma_{t 22}^{c r}
\end{array}\right]^{T}
$$

where the superscript $T$ denotes a transpose. Consequently, $\boldsymbol{N}$ becomes a 6 by 6 matrix, dictating the transformation of crack strains from local to global coordinates for each individual open crack. In the present study, since the crack planes are aligned with the local material coordinates, $\boldsymbol{N}$ can be written as,

$$
N=\left[\begin{array}{llllll}
1 & 0 & 0 & 0 & 0 & 0 \\
0 & 0 & 0 & 1 & 0 & 0 \\
0 & 0 & 0 & 0 & 0 & 0 \\
0 & 1 & 0 & 0 & 1 & 0 \\
0 & 0 & 1 & 0 & 0 & 0 \\
0 & 0 & 0 & 0 & 0 & 1
\end{array}\right]
$$


Similarly, the interface stresses at the crack interface, $\boldsymbol{s}^{c r}$, can be transferred to the global stress state, $\sigma$, through,

$$
\boldsymbol{s}^{c r}=\left\{\begin{array}{c}
\sigma_{n n}^{c r} \\
\tau_{t 1}^{c r} \\
\tau_{t 2}^{c r}
\end{array}\right\}=\boldsymbol{N}^{T} \boldsymbol{\sigma}
$$

The crack interface stresses are related to the local crack strains through,

$$
\boldsymbol{s}^{c r}=\boldsymbol{D}^{c r} e^{c r}
$$

where $\boldsymbol{D}^{c r}$ is the crack interface stiffness matrix that dictates the failure evolution in the post-peak strain softening regime. For two orthogonal cracks in a 3D solid, $\boldsymbol{D}^{c r}$ can be expanded as,

$$
\boldsymbol{D}^{c r}=\left[\begin{array}{llllll}
E_{1}^{c} & & & & & \\
& G_{11}^{c} & & & & \\
& & G_{12}^{c} & & & \\
& & & E_{2}^{c} & & \\
& & & & G_{21}^{c} & \\
& & & & & G_{22}^{c}
\end{array}\right]
$$

where $E_{1}^{c}$ and $E_{2}^{c}$ are the secant stiffness across the crack interfaces due to crack opening, and the rest of the components are the secant shear stiffness governed by crack sliding. These quantities identify the modes of failure and are related to the corresponding traction-separation laws with a characteristic length scale. The off-diagonal terms are assumed to be zero, indicating that there is no coupling between the normal and shear crack components. The coupling between the crack shear and opening displacements, known as crack dilatancy, has been extensively studied by Bažant and Gambarova, ${ }^{38}$ Walraven, ${ }^{39}$ Walraven and Reinhardt, ${ }^{40}$ and Gambarova and Karakoç. ${ }^{41}$ Further investigation on crack propagation, which delves into the sub-microstructure scale (at the atomic level) is needed to characterize the material behavior at the crack tip. Since the simple uncoupled relation in Eq. (9) is sufficient to dictate the effect of macroscopic strain softening behavior of a cracked material, crack dilatancy is not accounted for in this study. The determination of the components of the $\boldsymbol{D}^{c r}$ matrix for failure progression in a single 8HSW CMC ply is given in Section IV.C.3.

The constitutive relation for a continuum is,

$$
\boldsymbol{\sigma}=\boldsymbol{D}^{c o} \boldsymbol{\epsilon}^{c o}
$$

where $\boldsymbol{D}^{c o}$ is the continuum stiffness tensor. In the current study, since the woven CMC ply is modeled as a secant degrading solid in the pre-peak regime, $\boldsymbol{D}^{c o}$ is computed using the secant moduli at the onset of failure initiation. Combining Eq. (3), (4), and (10) results in,

$$
\boldsymbol{\sigma}=\boldsymbol{D}^{c o}\left[\boldsymbol{\epsilon}-\boldsymbol{\epsilon}^{c r}\right]=\boldsymbol{D}^{c o}\left[\boldsymbol{\epsilon}-\boldsymbol{N} \boldsymbol{e}^{c r}\right]
$$

The relation between the local crack strains and the total global strains can be obtained through Eq. (7), (8), and (11) as,

$$
\boldsymbol{e}^{c r}=\left[\boldsymbol{D}^{c r}+\boldsymbol{N}^{T} \boldsymbol{D}^{c o} \boldsymbol{N}\right]^{-1} \boldsymbol{N}^{T} \boldsymbol{D}^{c o} \boldsymbol{\epsilon}
$$

Finally, the relation between the total stress and total strain in the post-peak regime is computed by substituting Eq. (12) into Eq. (11),

$$
\boldsymbol{\sigma}=\left[\boldsymbol{D}^{c o}-\boldsymbol{D}^{c o} \boldsymbol{N}\left(\boldsymbol{D}^{c r}+\boldsymbol{N}^{T} \boldsymbol{D}^{c o} \boldsymbol{N}\right)^{-1} \boldsymbol{N}^{T} \boldsymbol{D}^{c o}\right] \boldsymbol{\epsilon}
$$

Noting that the original SCA by Rots et al. ${ }^{28}$ is formulated in an incremental fashion such that the loading path dependency is accounted for, however, Eq. (13) gives the total stress versus total strain relation, which is similar to that presented in. ${ }^{36,42,43}$ The total stress versus strain scheme is suitable for large time increments, and the stress at the end of each time increment can be determined based upon the corresponding traction-separation law. 


\section{IV.C.2. Characteristic Length Scale Associated with Traction-Separation Laws}

In the SCA, it is assumed that distributed cracks are "smeared" out over a certain width within a FE such that the effect of progressive cracking is represented by a macroscopic strain softening behavior in a continuum scheme as illustrated in Figure 14. The SCA is an outgrowth of the crack band model of Bazant and $\mathrm{Oh}^{27}$ which has been successfully used for capturing post-peak softening, for instance by Pineda et al. ${ }^{44}$ To restore mesh objectivity, a characteristic length is introduced such that the total amount of energy dissipated during failure in a continuum element is equal to the fracture toughness defined for a cohesive element of the same size. The fracture toughness, or the critical energy release rate, $G_{C}$, is defined by the area under the traction-separation law that dictates the cohesive behavior of crack propagation (see Figure $14(\mathrm{~b}))$ as,

$$
G_{C}=\int_{0}^{\delta_{f}} \sigma \mathrm{d} u
$$

where $u$ is the sum of crack displacements within the fracture zone, as schematically shown in Figure 14(a). In the SCA, $u$ represents the crack strain acting across a certain width within a finite element, denoted as the crack band width, $h$, which is shown in Figure 14(b). Assuming that all the cracks are uniformly distributed over the crack band, and since $u$ is the accumulation of all the crack strains over the fracture zone, it follows that,

$$
u=h \epsilon^{c r}
$$

If $g_{c}$ represents the area under the softening branch of the stress-strain response, then substituting Eq. (15) into Eq. (14) results in,

$$
G_{C}=\int_{0}^{\delta_{f}} \sigma\left(h \epsilon^{c r}\right) h \mathrm{~d} \epsilon^{c r}=h \int_{0}^{\epsilon_{f}^{c r}} \sigma\left(\epsilon^{c r}\right) \mathrm{d} \epsilon^{c r}=h g_{c}
$$

Therefore, the strain-based description for a softening material is related to the displacement-based tractionseparation laws through the characteristic length, $h$. In a FE setting, $h$ is chosen based upon the element type, element size, element shape, and the integration scheme. ${ }^{28}$

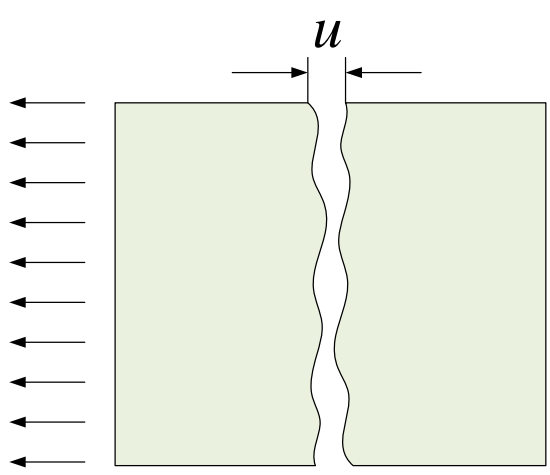

(a) Discrete crack.

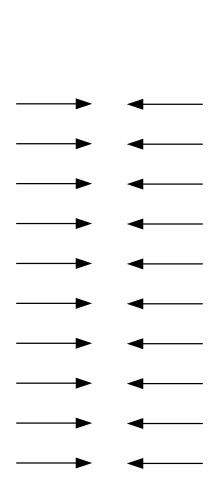

Figure 14. Discrete cracks are smeared out within a finite element.

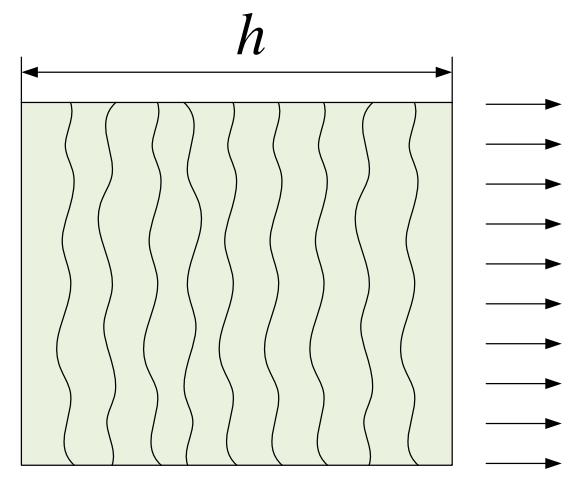

(b) Smeared crack.

\section{IV.C.3. Implementation of the SCA for Modeling the Failure Progression in a Single $8 H S W$ CMC Ply}

The unique failure characteristic of the oxide/oxide CMC is that the woven ply shows shear mode of failure at low stress states. This is evident from the $[0 / 90]_{\mathrm{s}}$ notched tension test that the two sites of strain concentration occurring in the early stages of loading are located in regions of predominant shear. In addition, when the shear failure is initiated, the CMC ply still demonstrates a certain degree of load-carrying capability before final fracture, however, the load transfer across the crack plane is limited so that the normal stress components cannot carry additional loading. Such behavior is evident from the $[+45 / 0 /-45 / 0]_{\mathrm{s}}$ un-notched tension test results which show that the tangent stiffness of the CMC laminate is reduced to half of the initial stiffness when the axial strain is beyond $0.25 \%$. It indicates that the $\pm 45^{\circ}$ layer has no contribution 


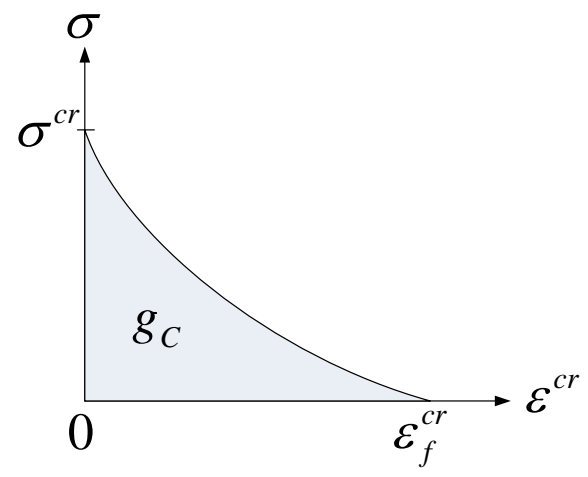

(a) Critical stress-strain curve.

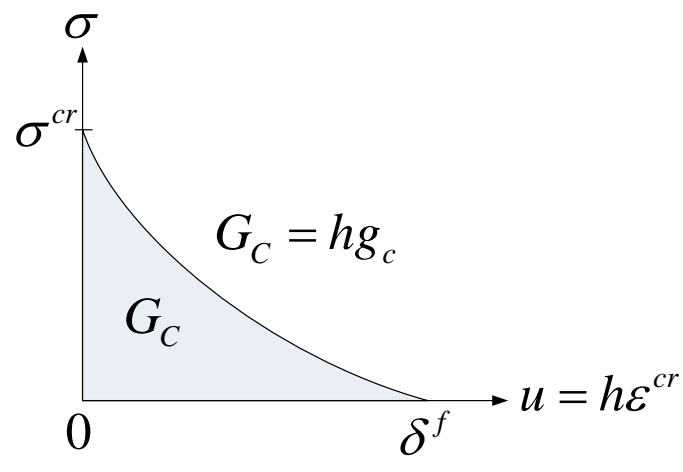

(b) Traction-separation law.

Figure 15. Stress-strain softening response is related to traction-separation law through a characteristic length, $h$.

to the laminate tangent stiffness at the onset of shear failure initiation, while these layers still can carry a low level of stress before they lose all the load-carrying capability completely.

In the present study, a linear traction-separation law was utilized to model the softening response of mode-I type of failure, as shown in Figure 16(a). The mode-I failure criterion is based upon the strain-tofailure measured in the un-notched $[0 / 90]_{\mathrm{s}}$ tension tests. Since the $\pm 45^{\circ}$ layers exhibit a progressive failure response, an anti-symmetric bi-linear traction-separation law, as shown in Figure 16(b), was employed to model the softening behavior due to mode-II type of failure. The critical strain values used in the mode-II failure criterion was characterized from the $[+45 / 0 /-45 / 0]_{\mathrm{s}}$ un-notched tension. The failure properties used in the FE model are summarized in Table 4.

It is worth noting that the experiment suggests a complicated mixed-mode failure response of the woven CMC ply. In the present study, it is assumed that when either mode-I or mode-II failure criterion is satisfied, the SCA will be utilized to model the post-peak softening behavior, and the traction-separation law will be re-sized to preserve the same fracture energy if the current critical stresses at the crack interface are lower than the values corresponding to the pure mode-I or mode-II conditions. The characterization of the mixedmode interaction is a subject of ongoing work, including utilizing a micromechanics based approach that considers the textile microstructure explicitly.

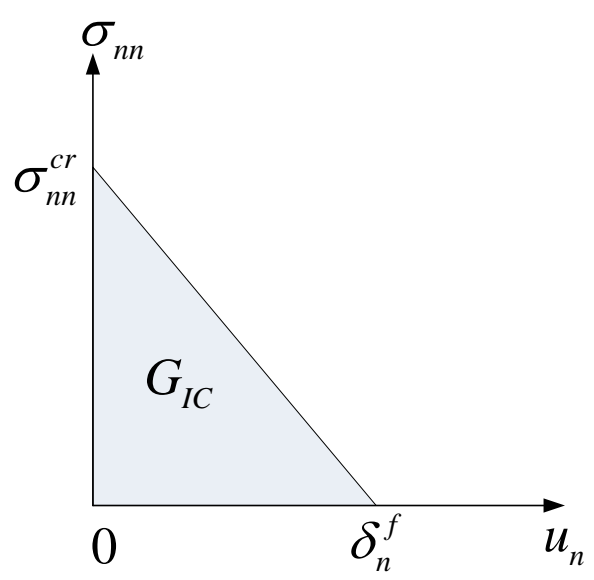

(a) Mode-I.

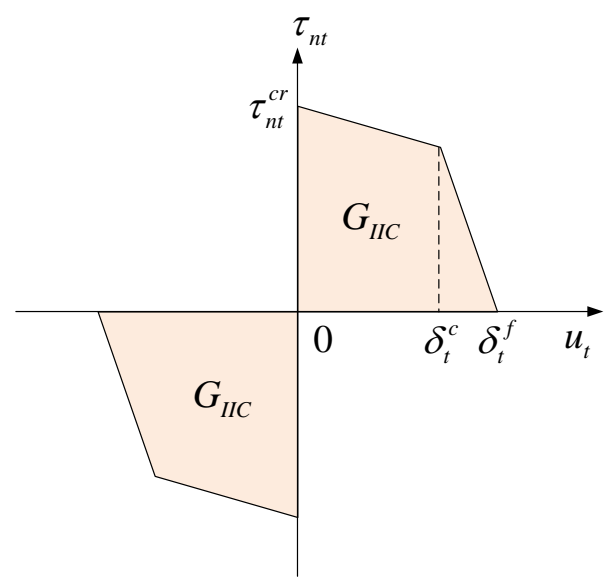

(b) Mode-II.

Figure 16. Traction-separation laws for modeling the failure responses of a single $8 \mathrm{HSW}$ CMC ply.

\section{Results and Discussion}

The predicted stress versus strain response for the $[0 / 90]_{\mathrm{s}}$ single-edge-notched tensile specimen is compared against the experimental results, as shown in Figure 17. The computational result shows good agree- 
Table 4. Failure properties used in the FE model.

\begin{tabular}{ccc}
\hline Failure mode & \multicolumn{2}{c}{ Properties } \\
\hline mode-I & $G_{I C}=4.00 \mathrm{~N} / \mathrm{mm}$ & $\delta_{n}^{f}=0.020 \mathrm{~mm}$ \\
mode-II & $G_{I I C}=3.05 \mathrm{~N} / \mathrm{mm}$ & $\delta_{t}^{c}=0.050 \mathrm{~mm}, \delta_{t}^{f}=0.055 \mathrm{~mm}$ \\
\hline
\end{tabular}

ment with experiment for both the stiffness and the ultimate tensile strength. The predicted tensile strain fields near the edge notch are plotted in Figure 18. Although the 8HSW woven ply was modeled as a homogeneous solid, the computed tensile strains are in good agreement with the measured values shown in Figure 10. The proposed model is able to capture the sites of strain localization observed in the experiment, as shown in Figure 18(a) and (b). Two cracks are initiated in regions of predominant shear and grow under mode-II dominant conditions. With continued loading, the cracks tend to propagate parallel to the loading direction, as shown in Figure 18(c)-(e). The continuous degradation of the shear modulus finally results in fiber fracture because progressively more axial load is transferred to the fibers, followed by a macroscopic strain softening response due to mode-I type of failure, as shown in Figure 18(f).

Utilizing the ply properties measured from the un-notched tension tests of the $[0 / 90]_{\mathrm{s}}$ and $[+45 / 0 /-$ $45 / 0]_{\mathrm{s}}$ lay-ups, the proposed computational model is able to predict the failure response of the $[0 / 90]_{\mathrm{S}}$ edge-notched tensile specimen response. Work is continuing to understand the effect of fracture toughness on the macroscopic strain softening and the mixed-mode interaction.

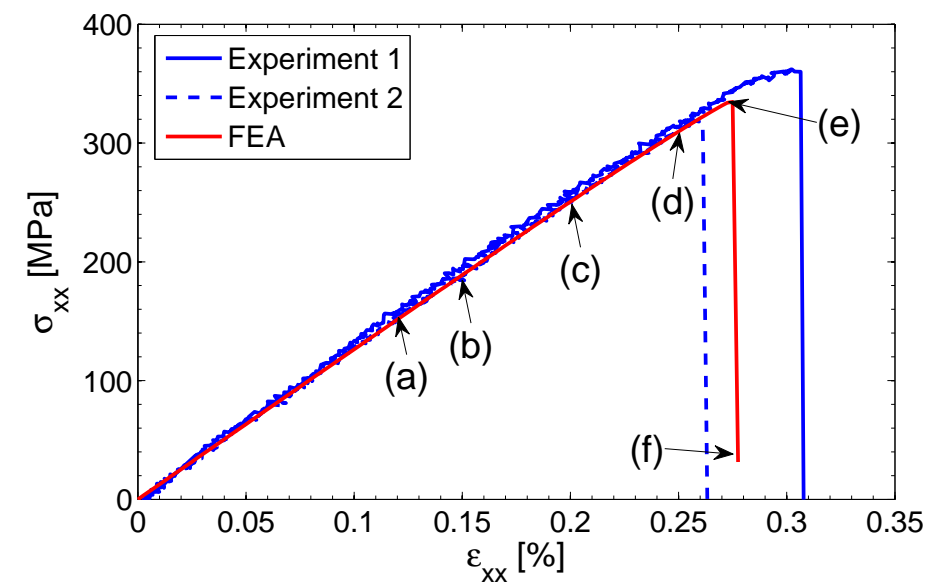

Figure 17. Comparison of the stress versus strain responses obtained from the experiment and the computational model for the $[0 / 90]_{\mathrm{s}}$ single-edge-notched tension test. The deformed shapes at the labeled points are shown in Figure 18.

\section{Conclusions}

Room-temperature tensile responses of oxide-oxide woven CMCs have been studied for two different lay-ups, including $[0 / 90]_{\mathrm{s}}$ and $[+45 / 0 /-45 / 0]_{\mathrm{s}}$. The DIC technique was utilized to map the deformation histories and identify modes of failure for both un-notched and single-edge-notched tensile tests. A laminalevel constitutive model was developed for a single ply of $8 \mathrm{HSW}$. It is assumed that the pre-peak nonlinear response is only attributed to the in-plane shear. The post-peak strain softening response was modeled using the SCA. A linear traction-separation law was employed to dictate mode-I failure, while mode-II failure was modeled using a bi-linear traction-separation law. Using the ply properties measured from the un-notched tensile tests of the $[0 / 90]_{\mathrm{s}}$ and $[+45 / 0 /-45 / 0]_{\mathrm{S}}$ lay-ups, the proposed computational model demonstrates an accurate prediction for the failure response of the $[0 / 90]_{\mathrm{s}}$ edge-notched tensile specimen. Future work is focused on the characterization of fracture energy and the effect of mixed-mode interaction in a single woven-ply, using micromechanics as a modeling strategy. 


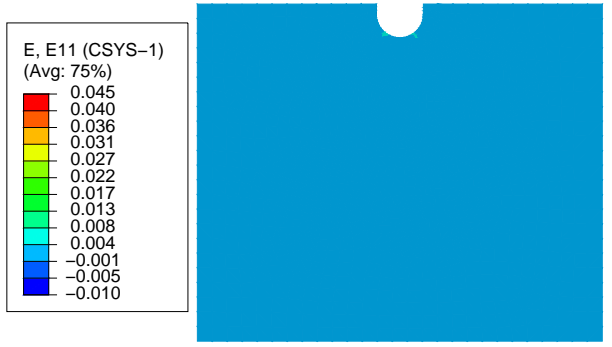

(a) At point (a).

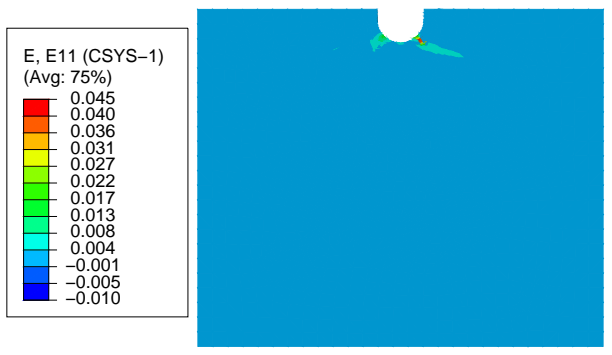

(c) At point (c).

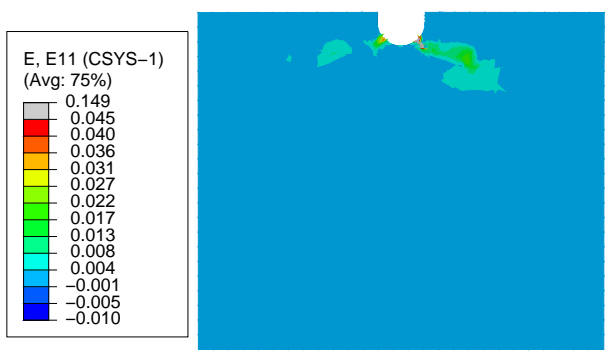

(e) At point (e).

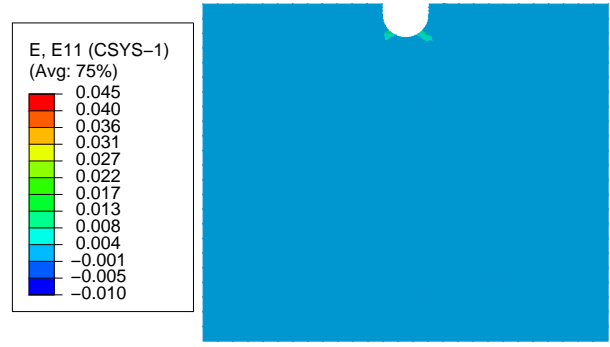

(b) At point (b).

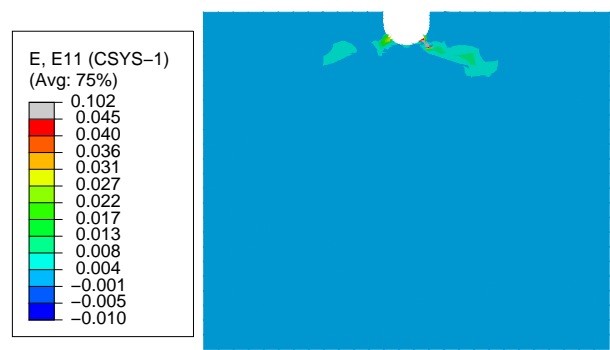

(d) At point (d).
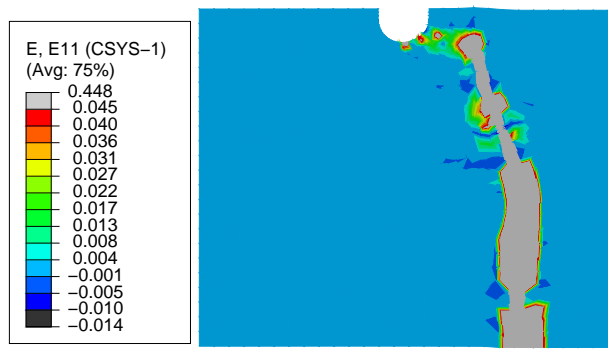

(f) At point (f).

Figure 18. Predicted tensile strains for the $[0 / 90]_{\mathrm{s}}$ single-edge-notched test.

\section{Acknowledgments}

The authors are grateful to Andy Zweda at COI Ceramics, Inc. for laminate preparation. Sponsorship from the Air Force Office of Scientific Research (AFOSR) Multiscale Structural Mechanics and Prognosis Program, with Dr. David Stargel as the program monitor is gratefully acknowledged.

\section{References}

${ }^{1}$ Nair, S. V. and Jakus, K., High Temperature Mechanical Behaviour of Ceramic Composites, Elsevier Inc., 1995.

${ }^{2}$ Levi, C. G., Yang, J. Y., Dalgleish, B. J., Zok, F. W., and Evans, A. G., "Processing and Performance of an All-Oxide Ceramic Composite," Journal of American Ceramic Society, Vol. 81, No. 8, 1998, pp. 2077-2086.

${ }^{3}$ Kramb, V. A., John, R., and Zawada, L. P., "Notched fracture behavior of an oxide / oxide ceramic-matrix composite," Vol. 96, 1999, pp. 3087-3096.

${ }^{4}$ Kramb, V. A., John, R., and Stubbs, D. A., "A study of the damage progression from notches in an oxide / oxide ceramic matrix composite using ultrasonic C-scans," Vol. 61, 2001, pp. 1561-1570.

${ }^{5}$ Mattoni, M. a. and Zok, F. W., "Strength and notch sensitivity of porous-matrix oxide composites," Journal of the American Ceramic Society, Vol. 88, No. 6, June 2005, pp. 1504-1513. doi:10.1111/j.1551-2916.2005.00299.x.

${ }^{6}$ McNulty, J. C., Zok, F. W., Genin, G. M., and Evans, A. G., "Notch-sensitivity of fiber-reinforced ceramic-matrix composites: effects of inelastic straining and volume-dependent strength," Journal of the American Ceramic Society, Vol. 82, No. 5, Dec. 2004, pp. 1217-1228. doi:10.1111/j.1151-2916.1999.tb01899.x.

${ }^{7}$ Kachanov, L. M., "On the Time to Rupture under Creep Conditions," Izvestiya Akademii Nauk SSSR, Otdeleniya Tekhnika Nauk, Vol. 8, No. 1, 1958, pp. $26-31$. 
${ }^{8}$ Talreja, R., "A Continuum Mechanics Characterization of Damage in Composite Materials," Proceedings of the Royal Society of London. A. Mathematical and Physical Sciences, Vol. 399, No. 1817, 1985, pp. 195-216. doi:10.1098/rspa.1985.0055.

$\checkmark{ }^{9}$ Kachanov, L. M., Introduction to Continuum Damage Mechanics, Martinus Nijhoff Publishers, Dortrecht, The Netherlands, 1986.

10 Schapery, R., "A theory of mechanical behavior of elastic media with growing damage and other changes in structure," Journal of the Mechanics and Physics of Solids, Vol. 38, No. 2, 1990, pp. 215-253. doi:10.1016/0022-5096(90)90035-3.

${ }^{11}$ Park, S. and Schapery, R., "A viscoelastic constitutive model for particulate composites with growing damage," International Journal of Solids and Structures, Vol. 34, No. 8, 1997, pp. 931-947. doi:10.1016/S0020-7683(96)00066-2.

12Lemaitre, J., A Course on Damage Mechanics, Springer-Verlag, Berlin, Heidelberg, New York, 2nd ed., 1996.

${ }^{13}$ Lemaitre, J. and Chaboche, J.-L., Mechanics of Solid Materials, Cambridge University Press.

${ }^{14}$ Lemaitre, J. and Desmorat, R., Engineering Damage Mechanics, Springer-Verlag, Berlin, Heidelberg, New York, 2005.

${ }^{15}$ Skrzypek, J. J., Anisotropic Behavior of Damaged Materials, Springer-Verlag, Berlin, Heidelberg, New York, 2003.

${ }^{16}$ Krajcinovic, D., Damage Mechanics, Elsevier, Amsterdam, The Netherlands, 1996.

${ }^{17}$ Talreja, R., "Transverse Cracking and Stiffness Reduction in Composite Laminates," Journal of Composite Materials, Vol. 19, No. 4, Jan. 1985, pp. 355-375. doi:10.1177/002199838501900404.

18 Matzenmiller, A., Lubliner, J., and Taylor, R., "A constitutive model for anisotropic damage in fiber-composites," Mechanics of Materials, Vol. 20, No. 2, April 1995, pp. 125-152. doi:10.1016/0167-6636(94)00053-0.

${ }^{19}$ Basu, S., Waas, A. M., and Ambur, D. R., "Computational modeling of damage growth in composite laminates," AIAA Journal, Vol. 41, No. 6, 2003, pp. 1158-1166. doi:10.2514/2.2059.

${ }^{20}$ Basu, S., Waas, A. M., and Ambur, D. R., "Prediction of progressive failure in multidirectional composite laminated panels," International Journal of Solids and Structures, Vol. 44, No. 9, 2007, pp. 2648-2676. doi:10.1016/j.ijsolstr.2006.08.010.

-21 Maimí, P., Camanho, P., Mayugo, J., and Dávila, C., "A continuum damage model for composite laminates: Part I Constitutive model," Mechanics of Materials, Vol. 39, No. 10, Oct. 2007, pp. 897-908. doi:10.1016/j.mechmat.2007.03.005.

-22 Maimí, P., Camanho, P., Mayugo, J., and Dávila, C., "A continuum damage model for composite laminates: Part II Computational implementation and validation," Mechanics of Materials, Vol. 39, No. 10, Oct. 2007, pp. 909-919. doi:10.1016/j.mechmat.2007.03.006.

${ }^{23}$ Pijaudier-Cabot, G. and Bažant, Z. P., "Nonlocal damage theory," Journal of Engineering Mechanics, Vol. 113, No. 10, Oct. 1987, pp. 1512-1533. doi:10.1061/(ASCE)0733-9399(1987)113:10(1512).

${ }^{24}$ Jirásek, M., "Comparative study on finite elements with embedded discontinuities," Computer Methods in Applied Mechanics and Engineering, Vol. 188, No. 1-3, July 2000, pp. 307-330. doi:10.1016/S0045-7825(99)00154-1.

${ }^{25}$ Askes, H., Pamin, J., and de Borst, R., "Dispersion analysis and element-free Galerkin solutions of second- and fourthorder gradient-enhanced damage models," International Journal for Numerical Methods in Engineering, Vol. 49, No. 6, Oct. 2000, pp. 811-832. doi:10.1002/1097-0207(20001030)49:6<811::AID-NME985>3.0.CO;2-9.

${ }^{26}$ Pamin, J., Askes, H., and de Borst, R., "Two gradient plasticity theories discretized with the element-free Galerkin method," Computer Methods in Applied Mechanics and Engineering, Vol. 192, No. 20-21, May 2003, pp. $2377-2403$. doi:10.1016/S0045-7825(03)00263-9.

${ }^{27}$ Bažant, Z. P. and Oh, B. H., "Crack band theory for fracture of concrete," Matériaux et Constructions, Vol. 16, No. 3, May 1983, pp. 155-177. doi:10.1007/BF02486267.

${ }^{28}$ Rots, G., Nauta, P., Kusters, G. M. A., and Blaauwendraad, J., "Smeared crack approach and fracture localization in concrete," HERON, Vol. 30, No. 1, 1985, pp. 1-48.

${ }^{29}$ Puck, A., "Failure analysis of FRP laminates by means of physically based phenomenological models," Composites Science and Technology, Vol. 58, No. 7, July 1998, pp. 1045-1067. doi:10.1016/S0266-3538(96)00140-6.

$\checkmark{ }^{30}$ Puck, A. and Schürmann, H., "Failure analysis of FRP laminates by means of physically based phenomenological models," Composites Science and Technology, Vol. 62, No. 12-13, Sept. 2002, pp. 1633-1662. doi:10.1016/S0266-3538(01)00208-1.

$\checkmark{ }^{31}$ Camanho, P. P., Dávila, C. G., Pinho, S. T., Iannucci, L., and Robinson, P., "Prediction of in situ strengths and matrix cracking in composites under transverse tension and in-plane shear," Composites Part A: Applied Science and Manufacturing, Vol. 37, No. 2, Feb. 2006, pp. 165-176. doi:10.1016/j.compositesa.2005.04.023.

\$2 Camanho, P., Maimí, P., and Dávila, C., "Prediction of size effects in notched laminates using continuum damage mechanics," Composites Science and Technology, Vol. 67, No. 13, Oct. 2007, pp. 2715-2727. doi:10.1016/j.compscitech.2007.02.005.

${ }^{33}$ Pineda, E. J., Bednarcyk, B. A., Waas, A. M., and Arnold, S. M., "Progressive failure of a unidirectional fiber-reinforced composite using the method of cells: Discretization objective computational results," International Journal of Solids and Structures, Vol. 50, No. 9, May 2013, pp. 1203-1216. doi:10.1016/j.ijsolstr.2012.12.003.

${ }^{34}$ Zawada, L. P., Hay, R. S., Lee, S. S., and Staehler, J., "Characterization and High-Temperature Mechanical Behavior of an Oxide / Oxide Composite," Vol. 90, No. 188004, 2003, pp. 981-990.

${ }^{35}$ Bažant, Z. P. and Cedolin, L., Stability of Structures: Elastic, Inelastic, Fracture, and Damage Theories, Oxford University Press, Inc., 1991.

${ }^{36}$ Zhang, D., Progressive Damage and Failure Analysis of 3D Textile Composites Subjected to Flexural Loading, Ph.D. thesis, University of Michigan, 2014.

- 37 de Borst, R. and Nauta, P., "Non-orthogonal cracks in a smeared finite element model," Engineering Computations, Vol. 2, No. 1, 1985, pp. 35-46. doi:10.1108/eb023599.

${ }^{38}$ Bažant, Z. P. and Gambarova, P. G., "Rough cracks in reinforced concrete," Journal of the Structural Division, Vol. 106, 1980, pp. 819-842.

${ }^{39}$ Walraven, J. C., Aggregate Interlock: A Theoretical and Experimental Analysis., Ph.D. thesis, Delft University of Technology, 1980.

${ }^{40}$ Walraven, J. C. and Reinhardt, H. W., "Theory and experiements on the mechanical behaviour of cracks in plain and reinforced concrete subjected to shear loading," HERON, Vol. 26, No. 1A. 
${ }^{41}$ Gambarova, P. G. and Karakoç, C., "A new approach to the analysis of the confinement role in regularly cracked concrete elements," Transactions 7th SMIRT Conference H (Paper H5/7)(Chicago, 1983), 1983, pp. 251-261.

${ }^{42}$ Heinrich, C. and Waas, A., "Investigation of progressive damage and fracture in laminated composites using the smeared crack approach," 53rd AIAA/ASME/ASCE/AHS/ASC Structures, Structural Dynamics and Materials Conference, Honolulu, Hawaii, April 2012, AIAA 2012-1537.

${ }^{43}$ Heinrich, C. and Waas, A. M., "Investigation of progressive damage and fracture in laminated composites using the smeared crack approach," CMC: Computers, Materials \& Continua, Vol. 35, No. 2, 2013, pp. $155-181$. doi:10.3970/cmc.2013.035.155.

${ }^{44}$ Pineda, E. J. and Waas, A. M., "Numerical implementation of a multiple-ISV thermodynamically-based work potential theory for modeling progressive damage and failure in fiber-reinforced laminates," International Journal of Fracture, Vol. 182, No. 1, 2013, pp. 93-122. doi:10.1007/s10704-013-9860-1. 